\title{
Abstract \\ Prevalence of colorectal diseases in patients who underwent colonoscopy in Teaching Hospital Peradeniya
}

Samarasinghe $\mathrm{B}^{1 *}$, Wijesuriya $\mathrm{N}^{1}$, Dissanayake $\mathrm{M}^{1}$, Bandara $\mathrm{D}^{1}$, Rajapaksha $\mathrm{T}^{1}$, Theswa $\mathrm{E}^{1}$

${ }^{1}$ Faculty of Medicine, University of Peradeniya.

\begin{abstract}
Background

Colonoscopy is an essential investigation in the management of colorectal conditions. The procedure is more sensitive than radiological imaging and offers a range of therapeutic options. Also it is the only method that enables tissue biopsy for pathological examination. Objective of this study was to estimate the prevalence of colorectal diseases in patients who underwent colonoscopy in Teaching Hospital Peradeniya.

\section{Method}

Colonoscopy data were collected from the database of Endoscopy unit of Teaching hospital Peradeniya from June 2014 to June 2015. Subjects with abnormal colonoscopy results were targeted for biopsy. Patients' demographic data, colonoscopy findings and histology reports were evaluated.

\section{Results}

A total number of 569 colonoscopies were performed over the one year period. Of them $296(52 \%)$ were female and $273(48 \%)$ were male patients. Their mean age was 56.8 years with a minimum of 8 years and maximum of 87 years. According to the colonoscopy results, 534 individuals $(93.8 \%)$ had normal colon, but in 35 patients $(6.15 \%)$ one or more abnormalities were reported. Among 35 abnormal colonoscopy results, there were $12(2.1 \%)$ adenocarcinoma, $10(1.7 \%)$ adenoma and $5(0.87 \%)$ polyps. Other disorders including ulcerative colitis, secondary deposit and inflamed colon were recorded in 8 patients $(1.4 \%)$. Furthermore, mean age of patients with adenocarcinoma was 57.5 years whereas mean age of patients with adenoma was 65.7 years. The overall complications recorded were 2 perforations $(0.35 \%)$.

\section{Conclusions}

Results of our study confirm that colonoscopy yields considerably useful diagnostic information with minimal complications in evaluating colorectal pathology, even though it is an invasive procedure.
\end{abstract}

Key words: Colonoscopy; Colonic Carcinoma; Colonic Adenoma; Colonic Ployps

Copyright: $($ C 2015 Samarasinghe B et al. This is an open access article distributed under the Creative Commons Attribution License, which permits unrestricted use, distribution, and reproduction in any medium, provided the original work is properly cited.

* Correspondence : bandula.s@gmail.com

Cite this abstract as: Samarasinghe B, Wijesuriya N, Dissanayake M, Bandara D, Rajapaksha T, Theswa E. Prevalence of colorectal diseases in patients who underwent colonoscopy in Teaching Hospital Peradeniya. Anuradhapura Medical Journal 2015;9 (2Supp):S36. DOI: http://dx.doi.org/10.4038/amj.v9i2Supp 
